Research Article Genetics of Microorganisms

\title{
Analysis of potential virulence genes and competence to transformation in Haemophilus influenzae biotype aegyptius associated with Brazilian Purpuric Fever
}

\author{
Rafaella Fabiana Carneiro Pereira ${ }^{1}$, Thais Holtz Theizen ${ }^{1}$, Daisy Machado ${ }^{1}$, João Paulo de Oliveira \\ Guarnieri $^{2}$, Gabriel Piccirillo Gomide ${ }^{2}$, Luciana Maria de Hollanda ${ }^{1}$ and Marcelo Lancellotti ${ }^{1,2}$ (D) \\ ${ }^{1}$ Universidade Estadual de Campinas, Departamento de Bioquímica e Biologia Tecidual, Instituto de \\ Biologia, Campinas, SP, Brazil. \\ ${ }^{2}$ Universidade Estadual de Campinas - UNICAMP, Faculdade de Ciências Farmacêuticas - FCF, Campinas, \\ SP, Brazil.
}

\begin{abstract}
Brazilian Purpuric Fever (BPF) is a hemorrhagic pediatric illness caused by Haemophilus influenzae biogroup aegyptius (Hae), a bacterium that was formerly associated with self-limited purulent conjunctivitis. BPF is assumed to be eradicated. However, the virulence mechanisms inherent to Hae strains associated with BPF is still a mystery and deficient in studies. Here, we aim to analyze the role of the autotransporter genes related to adherence and colonization las, tabA1, and hadA genes through RT-qPCR expression profiling and knockout mutants. Relative quantification by real-time PCR after infection in human cells and infant rat model suggests that las was initially downregulated probably duo to immune evasion, tabA1, and hadA were overexpressed in general, suggesting an active role of TabA1 and HadA1 adhesins in Hae in vitro and in vivo. Transformation attempts were unsuccessful despite the use of multiple technical approaches and in silico analysis revealed that Hae lacks genes related to competence in Haemophilus, which could be part of the elucidation of the difficulty of genetically manipulating Hae strains.
\end{abstract}

Keywords: Haemophilus influenzae biotype aegyptius, Brazilian Purpuric Fever, virulence, qPCR, competence.

Received: February 21, 2020; Accepted: November 18, 2020.

\section{Introduction}

Haemophilus influenzae biogroup aegyptius (Hae) was formerly associated with seasonal epidemics of self-limited purulent conjunctivitis ("pink eye") until the 1980s, when an emergent clone of Hae was identified as the etiological agent of Brazilian Purpuric Fever (BPF) (Brenner et al., 1988; Harrison et al., 2008). BPF is a fulminant pediatric disease characterized by conjunctivitis, high fever, purpura, and sepsis. BPF major outbreaks arose from 1984 to 1990 in São Paulo, Brazil. Sporadic cases have been registered in Australia, USA (Harrison et al., 2008) and more recently in 2007 in Pará, Brazil (Santana-Porto et al., 2009). BPF is a disease with mandatory reporting in Brazil. The invasive unique phenotype highlights Hae associated with BPF (HaeBPF) from other Haemophilus influenzae strains (Hi).

Potential virulence factors such as pilus proteins and lipopolysaccharide have been studied in vitro with endothelial cells (Quinn et al., 1995; Weyant et al., 1994) and in infant rats (Rubin and St Geme, 1993); however, the origin and virulence mechanisms of Hae-BPF is still unknown. A potential pathogenic determinant in Hae is the las gene, a member of the AIDA-I/VirG/PerT family of virulence-associated

Send correspondence to Marcelo Lancellotti. Universidade Estadual de Campinas, Departamento de Bioquímica e Biologia Tecidual, Instituto de Biologia, Rua Monteiro Lobato, 255, 13.083-970, Campinas, SP, Brazil. E-mail: mlancell@ unicamp.br. autotransporters (ATs). Homology and sequence analysis suggest that las emerged from Hi lav (Davis et al., 2001).

Genome comparative analysis identified that Hae accessory genome has 21 specific Hae-BPF putative genes (Strouts et al., 2012; Pereira et al., 2019) and a much richer repertoire of AT adhesins in comparison to another available genome of Haemophilus genus. A total of eight new trimeric autotransporter adhesins (TAAs) was described in Hae (BPF and conjunctivitis isolates) and are present as homologs, termed $t a b A$ - for the Hae-BPF alleles, or $\operatorname{tah} A$ - for the Hae non-BPF alleles. TabA1 was characterized as the $\mathrm{P} 145$ protein (Strouts et al., 2012), identified in Hae isolates from animals (Rubin and Rizvi, 1991; Rubin, 1995). The tabAl and tahA1 loci are different in the coding sequences, suggesting different functions, and $t a b A 1$, possess two additional coding sequences, HIBPF06250 and IS1016 (absent in non-BPF strains) (Strouts et al., 2012). The formerly described as the Haemophilus capsulation locus-associated insertion sequence IS1016 has been related with unusual and invasive virulence of nontypeable Hi (NTHI) isolates.

HadA is a TAA unique to BPF associated strains and belongs to the 'oligomeric coiled-coil adhesin' (Oca) family found in virulent bacterial isolates. According to Serruto et al. (2009), hadA gene is missing in Hi Rd KW20 and non -BPF Hae F1947, but these strains present the sequences flanking this gene. Because the GC composition of hadA is significantly different from the rest of the Hi genomes (Serruto et al., 2009) and the F3031 genome (Strouts et al., 2012), it is 
believed hadA has been acquired by horizontal transfer (HT) (Serruto et al., 2009).

Since HT is a crucial element in the evolution and emergence of bacterial pathogens, a possible explanation for the clonal emergence of Hae-BPF is the acquisition of one or more virulence genes by HT (Bartlett, 2006, Diep et al., 2006). $\mathrm{Hi}$ is a bacterium naturally competent to transformation (Mell et al., 2011, Sinha et al., 2012). Sinha et al. (2012) identified the Sxy-dependent cyclic AMP receptor protein (CRP-S) regulon required for natural transformation in $\mathrm{Hi}$. The genetic manipulation in Hae could be an important tool to elucidate the role of virulence genes in Hae-BPF. However, it was only once registered as successful in the literature (Segada and Lesse, 1997); several attempts were made to obtain mutants strains but all failed (Li et al., 2003, Serruto et al., 2009).

Here, we describe for the first time the expression of three potential virulence-associated AT genes of Hae-BPF in human cells and in the infant rat model. We also tried to elucidate the puzzling enigma of Hae competence to transformation.

\section{Material and Methods}

\section{Bacterial growth and DNA extraction}

Growth conditions and DNA extraction protocol followed the methods described previously (Varela et al., 2014; Cury et al., 2014). Bacterial strains used in this work are described in Table 1.

\section{In vitro infection assays}

In vitro infection assays were based on methods described by Pereira et al. (2011). Briefly, A549 (human pulmonary epithelial carcinoma) and Hec1b (human endometrium adenocarcinoma) cells were grown in RPMI-1640 medium (Cultilab, Campinas, Brazil) supplemented with $10 \%$ of fetal bovine serum (Gibco, USA). Cells suspensions were seeded in 12-well tissue culture plates and incubated until confluence of cell monolayers. A total of $50 \mu \mathrm{l}$ of the bacterial suspensions with approximately $1.10^{7} \mathrm{CFU}$ of F3031, F3033, KC1018, and ATCC11116 strains were inoculated in). After an incubation time of 6 hours at $37^{\circ} \mathrm{C}$ with $5 \% \mathrm{CO}_{2}$, adherent bacteria were recovered in chocolate agar, grown as described previously and used for RT-qPCR analysis. All assays were performed with technical triplicates.

\section{Animal model infection assays}

Litters of Sprague-Dawley rats (Rattus norvegicus) were acquired from "Centro Multidisciplinar para Investigação Biológica na Área de Ciência em Animais de Laboratório CEMIB/UNICAMP" (http://www.cemib.unicamp.br). They were bred in a specific-pathogen-free facility at IB-UNICAMP and were 8 to 10 days old. The animal model and protocol were based on previous studies with Hae (Rubin and Carlone, 1989; Rubin and St Geme, 1993). Briefly, a single dose of $1.10^{5} \mathrm{CFU}$ of bacteria was given intraperitoneally and animal infection was performed in groups as described in Table 2. After a period of 24 and 48 hours, animals were anesthetized by ketamine/xylasin use $(50 / 5 \mathrm{mg} / \mathrm{kg})$ before euthanasia, and blood was obtained by heart puncture. Bacteria were recovered in chocolate agar, grown as described previously, and used for further analysis.

The protocol for animal practice was approved in accordance with relevant guidelines and regulations: "Comissão de Ética e Uso de Animais - CEUA - UNICAMP" Comission of Ethics in animal use protocol number: 3197-1 (http://www.ib.unicamp.br/comissoes/ceua)".

\section{RNA extraction}

Bacterial isolates from in vitro and in vivo assays were grown as previously described. Extraction of total RNA was in Trizol Reagent ${ }^{\circledR}$ protocol. RNA concentration and quality

Table 1 - Bacterial strains used in this work.

\begin{tabular}{|c|c|c|c|}
\hline Strain & Alias & Bacteria & GenBank acession no. \\
\hline F3031 & 254 & Hae-BPF & FQ670178 \\
\hline F3033 & 258 & Hae-BPF & NA \\
\hline F3030 & 219 & Hae-BPF & LNKQ00000000 \\
\hline F3039 & 321 & Hae-BPF & LNKN00000000 \\
\hline F3042 & 284 & Hae-BPF & LNKO00000000 \\
\hline F3283 & 406 & Hae-BPF & LNKP00000000 \\
\hline F1949 & Karina & Hae-BPF & LNKS00000000 \\
\hline F3028 & 329 & Hae-BPF & СР043771 \\
\hline F3037 & 167 & Hae-BPF & CP043772 \\
\hline F3043 & 55 & $\mathrm{Hae}$ & CP043811 \\
\hline F3052 & 232 & $\mathrm{Hae}$ & СР043810 \\
\hline F3047 & 73 & Hae & FQ670204 \\
\hline $\mathrm{KC} 1018$ & - & Hae & LNKR00000000 \\
\hline ATCC11116 & - & Hae & AFBC00000000 \\
\hline RdKW20 & - & Hi type d & L42023 \\
\hline$\beta$-lac & Hib- $\beta$ lac & Hi type b & NA \\
\hline JM109 & - & Competent $E$. coli & - \\
\hline
\end{tabular}


Table 2 - Recovery of animal-passaged strains from infection assays.

\begin{tabular}{cccc}
\hline Strain & No. animals with positive blood culture/ total \\
\hline & 24 hours & $2 / 5$ & $0 / 5$ \\
F3031 & $2 / 5$ & $2 / 5$ \\
F3033 & $0 / 5$ & $0 / 5$ \\
KC1018 & $0 / 3$ & - \\
ATCC11116 & 0 & 0 \\
\hline
\end{tabular}

were determined by NanoDrop (NanoDrop ${ }^{\circledR} 2000$ - Thermo Scientific).

\section{Primer design and validation}

Gene sequences were retrieved from F303 genome: alaS (alanyl-tRNA synthetase), era (ERA-binding protein), gmk (guanylate kinase), gyrA (subunit A of DNA gyrase), map (methionine aminopeptidase), primase, recA (recombinase A), recF (Replication and DNA repair protein RecF), rho (Rho transcription termination factor), rpoA (alpha subunit of RNA polymerase), rpoC (beta subunit of RNA polymerase) and $r p o D$ (sigma of RNA polymerase), las, tabAl, and hadA. Primers for qPCR and transformation assays were designed using Primer3Plus software (available at https://primer3plus. $\mathrm{com} /$ ) and the sequences are listed in Table S1. qPCR primers were designed with the following criteria: total length ranging from 20 to $25 \mathrm{bp}$, melting temperature of $60^{\circ} \mathrm{C}$, amplicon length ranging from 70 to $150 \mathrm{bp}$, average $\mathrm{GC}$ content of 50 $\%$. All the primers pairs were evaluated with conventional PCR with genomic DNA to check specificity. $t a b A$ qPCR primers target a conserved region shared between the homologous genes tabAl in Hae-BPF and tahAl in non-BPF Hae strains previously described (Strouts et al., 2012).

\section{RNA reverse transcription and real-time PCR}

cDNA synthesis and qPCR (RT-qPCR) assays were carried out using the StepOnePlus ${ }^{\text {TM }}$ Real-Time PCR System (Applied Biosystems). Reactions were performed with the SuperScript $^{\circledR}$ III Platinum ${ }^{\circledR}$ (Invitrogen) with SYBR Green Fast (Applied Biosystems). Reactions contained $50 \mathrm{ng}$ of total RNA and $600 \mathrm{nM}$ of each primer. PCR conditions were 50 ${ }^{\circ} \mathrm{C}$ for $15 \mathrm{~min}$ followed by $95{ }^{\circ} \mathrm{C}$ for $2 \mathrm{~min}, 45$ cycles of 95 ${ }^{\circ} \mathrm{C}$ for $15 \mathrm{~s}$ and $60{ }^{\circ} \mathrm{C}$ for $1 \mathrm{~min}$. Primer pair specificity was evaluated by melting curve analysis and gel electrophoresis. Assays were performed with technical triplicates.

\section{Evaluation of candidate reference genes in Hae}

The expression of candidate reference genes was evaluated on three distinct experimental conditions: 1 . Bacteria recovered from in vitro infection in A549 and Hec1b cells; 2. Bacteria recovered from in vivo infection; 3. Bacterial stock samples (no infection passage). The following strains were used: F3031_A, F3031_S, F3033, F3033_S, ATCC11116, $\beta$-lac, and $\beta$-lac_H. The suffixes_A,_H,_S, and_S48 correspond to samples isolated from $\mathrm{A} \overline{5} 49, \mathrm{Hec} \mathrm{lb}$, and animal infection for 24 and 48 hours, respectively; samples with no suffix correspond to the stock samples (e.g., F3031_S is the F3031 isolated sample from in vivo 24 hours infection, and F3031 is the stock sample). The stability of candidate reference genes was performed with the geNorm algorithm (Vandesompele et al., 2002). An expression stability coefficient for candidate genes was obtained and genes with the lower coefficient were considered stable and used for RT-qPCR assays.

\section{Relative quantification of potential virulence genes in Hae}

The expression of las, $\operatorname{tabA1/tahAl,\text {and}hadA\text {genes}}$ were evaluated by RT-qPCR on three distinct experimental conditions: 1. Bacteria recovered from in vitro infection in A549 and Heclb cells; 2. Bacteria recovered from in vivo infection; 3. Bacterial stock samples (reference group). The following groups were used: 1. F3031: F3031, F3031_A, F3031 H, F3031 S; 2. F3033: F3033, F3033 A, F3033 S, F3033_S48; 3. KC1018: KC1018, KC1018_A, KC1018_H; 4. ATCC1116: ATCC1116, ATCC1116 A, ATCC1116 H. The relative quantification of each gene was calculated using the $2^{-\Delta \Delta \mathrm{Ct}}$ with $g y r A, r p o C$, and $r p o D$ used as reference genes and stock samples used as reference (control) for normalization.

\section{Statistical analysis}

For statistical analysis, the relative expression of each gene was compared between group samples using One-way analysis of variance (ANOVA), with the Tukey post hoc test. A $\mathrm{p}$-value of 0.05 indicated a statistically significant difference.

\section{Construction of mutant knockout vectors of Hae virulence genes}

Recombinant DNA protocols such as cloning plasmids, PCR amplifications, restriction digestion, insertion of resistance cassettes and transformation in Escherichia coli JM109 were performed as described previously (Hollanda et al., 2011). Detailed information regarding recombinant protocols are available upon request. Briefly, specific regions of las, tabA1, and hadA were amplified with primers listed in Table S1. The purified PCR product were cloned into pGEMT Easy System II (Invitrogen), and the construction was digested on specific sites allowing the insertion of ermAM cassette harboring a gene encoding erythromycin resistance. Positive clones were checked by PCR analysis using an oligonucleotide specific to the target gene and another specific to the ermAM cassette.

\section{Transformation assays in Hae}

Hae-BPF strains F3031, F3033, and F1946 growth and transformation experiments were performed with four different approaches based on the protocols with the graphene oxide nanoparticle mesoporous silica SBA15 as previously described (Varela et al. 2014), and chemical treatment with calcium chloride $\left(\mathrm{CaCl}_{2}\right)$ followed by a heat shock (Dagert and Ehrlich, 1979): 1.Treatment with SBA15; 2. Chemical 


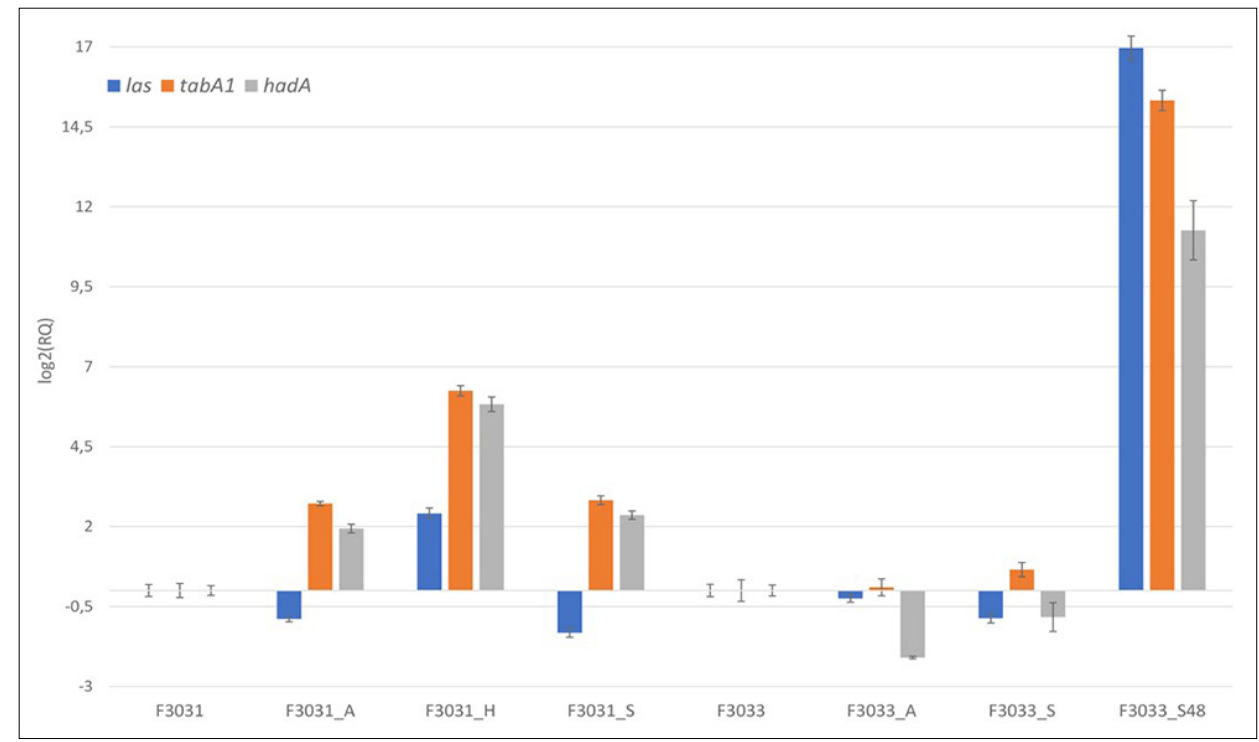

Figure 1. Relative expression of las, tabAl, and hadA genes for Hae-BPF F3031 and F3033 using gyrA, rpoC and rpoD as reference genes. Relative quantification (RQ) data were normalized with control samples (bacteria not recovered from infection assays). Bars represent the error associated with the reported RQ value for each target.

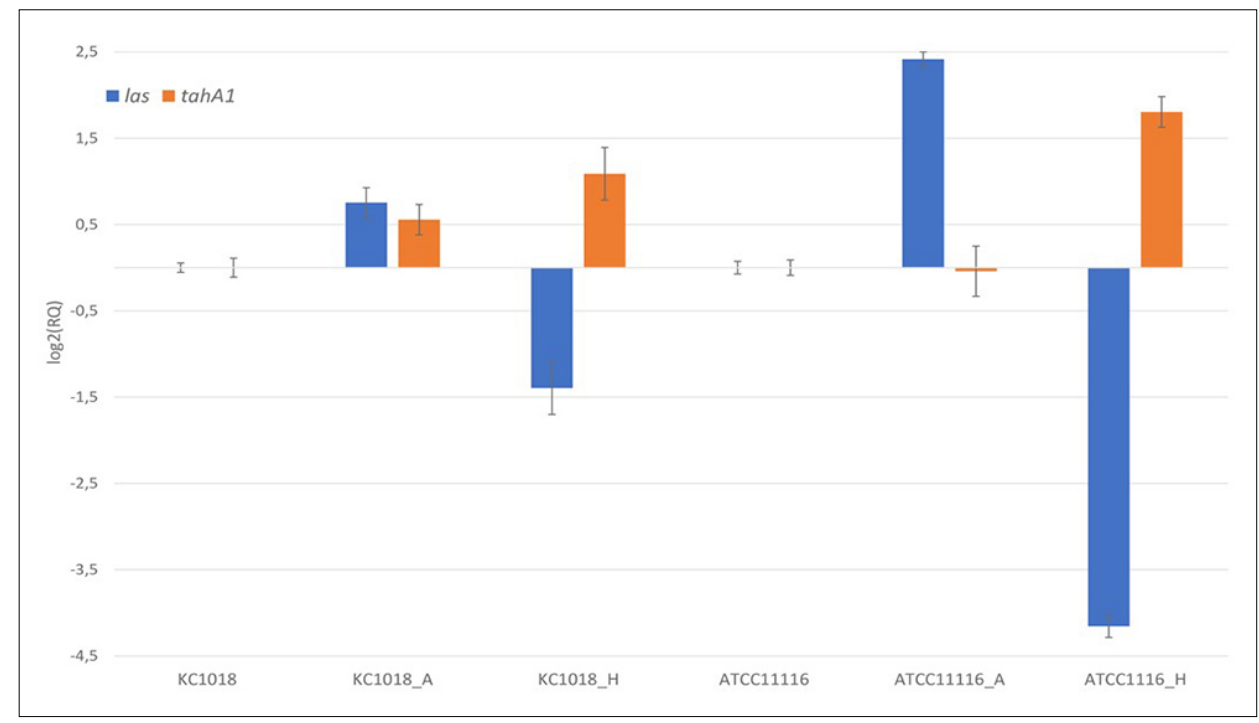

Figure 2. Relative expression of las and tahAl genes or Hae $\mathrm{KC} 1018$ and ATCC11116 using gyrA, rpoC and rpoD as reference genes. Relative quantification (RQ) data were normalized with control samples (bacteria not recovered from infection assays). Bars represent the error associated with the reported RQ value for each target.

and thermal treatment; 3 . Chemical and thermal treatment with SBA15; 4. No treatment.

Bacterial cells were incubated with the constructed vectors harboring a disrupted las, tabAl or hadA gene and the SBA nanoparticles at a final concentration of $30 \mathrm{ng}$ for 30 minutes. Subsequently, $1 \mathrm{~mL}$ of supplemented BHI broth supplemented with NAD/ hemin $2 / 10 \mu \mathrm{g} / \mathrm{mL}$ was added and the cells were incubated at $37{ }^{\circ} \mathrm{C}$ with $5 \% \mathrm{CO}_{2}$ for 4 hours. Cells were then transferred to $\mathrm{BHI}$ agar supplemented with $\mathrm{NAD} / \mathrm{hemin} 2 / 10 \mu \mathrm{g} / \mathrm{mL}$ and $7 \mu \mathrm{g} / \mathrm{mL}$ of erythromycin and incubated for 48 hours under the same described conditions. All transformation assays were performed in three replicates at least and negative controls were made to ensure the viability and absence of contamination.

\section{Comparative transformation in $\mathrm{Hae}$ and $\mathrm{Hi}$}

Transformation capacity of Hae F3031, F3033, KC1018, ATCCC11116 and established competent strains of Hi (Rd KW20 and $\beta$-lac) was compared using the protocol and the pLAN78 las::ermAM vector which contains the ATCC11116 las gene fused to the ermAM resistance cassette (Cury et al., 2014).

\section{In silico evaluation of CRP-S genes in Hae}

Sequences of the CRP-S regulon genes (pilA, pilB, pilC, pilD, comA, comB, comE, comF, comE, comO, comP, comEI, pilF2, rec2, ligA, HI0659, HI0660, HI1631, comM, $\operatorname{Rad} C$, and $s s b$ ) were obtained from Rd KW20. Sequences 
were used for a BLASTn search against a custom database with the genomes of strains listed in Table 1.

\section{Results}

\section{In vitro and in vivo assays}

F3031, F3033, KC1018, and ATCC1116 isolates were successfully recovered from A459 and $\mathrm{Hec} 1 \mathrm{~b}$ infection assays. Animal-passaged isolation is described in Table 2; only Hae associated with BPF were recovered from the animal model.

\section{Expression of candidate reference and potential virulence genes in $\mathrm{Hae}$}

Twelve genes were evaluated as possible candidates for Hae reference gene for RT-qPCR assays. We obtained an expression stability coefficient for each gene across three different experimental contexts using geNorm ranging from 1.7881 to 4.3479 . The genes with the lowest stability coefficient were considered the most stables and were selected: gyrA (1.7881), rpoC (1.803) and rpoD (1.9115) (see Table $\mathrm{S} 2$ for all expression stability coefficients).

We compared the expression of virulence genes of the original strain (stock) with strains recovered from in vitro and in vivo infection. The relative quantification of las, tabA1/ tahAl, and hadA genes are presented in Figures 1 and 2 (RQ values are available in Table S3). Hae-BPF cellular and animalpassaged strains showed differentiated expression of the las and $t a b A 1$ genes compared to the control samples $(\mathrm{p}<0.001)$, except tabA1 and las in F3033_A. The animal animal-passaged strains with different times of infection showed different profiles in las expression: the 24 hours samples (F3031_S and F3033_S) showed a significant decrease in las expression whereas the F3033_S48 overexpressed this gene (16.9-fold). It is possible that las has a potential negative regulation during initial contact with the host, having a more expressive role in the evolution of the disease. In the non-BPF KC1018_H and ATCC11116_H strains, a reduced expression of las was observed $(\mathrm{p}<0.001)$.

Expression of $t a b A 1$ in both strains isolated from the animal model (F3031_S and F3033_S48) and F3031 isolated from cells was significantly higher when compared to control stock sample $(p<0.001)$. Increased expression of this gene in F3031 could be related to Hae virulence and survival in the host, since TabA1 is believed to be the P145 protein (Strouts et al., 2012). However, the expression of tabAl in F3033 was similar in control and infection samples. In the conjunctivitis samples (KC1018 and ATCC11116), tahAl gene was also overexpressed $(\mathrm{p}<0.001)$ except in ATCCC11116_A, suggesting a possible role in virulence in non-BPF samples.

Expression of the specific Hae-BPF adhesin/invasin hadA were evaluated in F3031 and F3033. F3031_A, H, and $\mathrm{S}$ showed an increased expression $(\mathrm{p}<0.001)$. Although the F3033_A and S isolates presented not significant changes in hadA expression, F3033_S48 showed a higher hadA expression (128152-fold change) $(\mathrm{p}<0.001)$. The HadA role in the adherence and invasion in human host cells had already been observed (Serruto et al., 2009).

\section{Transformation capacity in Hae strains}

Since Hae capacity to transform is a controversial subject, new methodologies were used with the addition of silica nanotubes and chemical and thermal treatment. However, we could not obtain a knockout Hae strain for las, tabAl, or hadA gene. The transcriptional fusion vector pLAN78 was used to evaluate the transformation capacity in Hae. pLAN78 was already successfully transferred to $N$. meningitidis and Hi strains (Cury et al., 2014). Hae strains were again not competent to transformation whereas 19 and $4 \mathrm{CFU}$ of $\mathrm{Hi}$ RdKW20 and Hi $\beta$-lac, respectively, were observed. All negative controls grown, ensuring that the transformation conditions did not compromised the bacterial viability.

BLASTn search results of the twenty-six CRP-S regulon genes in Hae genomes are shown in Table 3. We observed that Hae strains do not have all the genes related to the competence

Table 3 - Analysis of the CRP-S regulon in Hae strains.

\begin{tabular}{|c|c|c|c|}
\hline Strain & HI0659 & HI0660 & HI1631 \\
\hline F3031 & - & - & - \\
\hline F3030 & - & - & - \\
\hline F3039 & - & - & - \\
\hline F3042 & - & - & - \\
\hline F3283 & - & - & - \\
\hline \multicolumn{4}{|l|}{ F1949 } \\
\hline F3028 & - & - & - \\
\hline F3037 & - & - & - \\
\hline F3043 & + & + & - \\
\hline F3052 & + & + & - \\
\hline F3047 & + & + & - \\
\hline KC1018 & + & + & - \\
\hline ATCC11116 & + & + & - \\
\hline RdKW20 & + & + & + \\
\hline
\end{tabular}

+: presence; -: absence 
of Hi previously identified by Sinha et al. (2012). Three regulon genes, HI0659, HI0660, and HII631, are absent in all Hae-BPF strains analyzed. Conjunctivitis strains lack the HI1631 gene.

\section{Discussion}

In animal model experiments, Hae-BPF strains were recovered after 24 and 48 hours of infection while conjunctivitis Hae strains failed to cause bacteremia in infant rats. Rubin and Carlone (1989) had similar data in which Hae associated with BPF caused more expressive bacteremia when compared to non-BPF strains. In a total of 50 infant rats injected with non-BPF strains, only one animal showed bacteremia (Carlone et al., 1989). Those findings suggest that Hae-BPF strains are, not only more virulent but present specific factors involved in immune evasion in infant rats and human hosts.

Few genes have been related to Hae unique virulence among which are the ATs las, tabAl, and hadA, whose expression was evaluated in strains after in vitro an in vivo infection. Overall results imply that in cellular and animal infection models, las is initially downregulated in Hae-BPF. Our data showed that las was overexpressed in the Hae_BPF F3033 in the latter stages of the infection. In a previous study, our group showed that the transfer of las in NTHi strains caused a higher production of the tumor necrose factor alpha TNF- $\alpha$ and interleukin 10 - IL10 in Hec1b versus the wildtype strains (Cury et al., 2014). The las gene in Hae (lav in non-BPF $H$. influenzae) is evolutionarily related to the $\mathrm{AT}$ autB prone to phase variation in N. meningitidis (Davis et al., 2001). Arenas et al. (2016) reported that autB is switched off in most of $N$. meningitidis isolates probably related to immune evasion. According to their findings, AutB synthesis promotes biofilm formation and may facilitate colonization of host tissues. The Las function in Hae is still unknown. However, our findings indicate a similar role to the meningococcal $a u t B$ and that phase variation could be a major player in the las expression in the host.

The specific Hae-BPF genes $t a b A 1$ and hadA gene appear to play an active function in infant rats and cell infection. TabA1 has been recognized as the $145-\mathrm{kDa}$ P145 protein, a conserved phase-variable surface protein (Strouts et al., 2012). Although the expression of P145 did not contribute to a pathogenic behavior in the animal model (Rubin, 1995), this AT seems to be important in Hae survival in the host environment, since specific anti-P145 antibody showed bactericidal and protective activity against Hae-BPF in infant rats (Rubin and Rizvi., 1991). Serruto et al. (2009) over-expressed HadA in non-pathogenic $E$. coli and observed bacterial aggregation, microcolony formation and invasion in Chang (human conjunctival) and HUVEC (human umbilical vein endothelial) cells. Nevertheless, antibodies against this adhesin may inhibit Hae adhesion in Chang cells. The hadA gene is unique to Hae associated with BPF strains, characterized as a determinant of Hae virulence (Serruto et al., 2009; Strouts et al., 2012), although how this adhesin interacts with the host and with other virulence factors is still unknown.

Here we attempt to genetically manipulate Hae strains to determinate how the knockout of las, tabAl and hadA would affect Hae virulence. After unsuccessful attempts, we hypothesized that, or the mutants were inviable (i.e. the three genes would be essentials to Hae growth and survival), or Hae was unable to transform. We performed a comparative transformation assay with Hae with a vector with a nondeleterious effect to investigate the first hypothesis. Over again, Hae strains associated or not with BPF were not competent to transformation. The unsuccess of genetic manipulation of Hae was already reported (Serruto et al., 2009; Li et al., 2003). Through sequence analysis of CPR-S regulon genes, we discovered that Hae-BPF strains do not harbor the HII631, $H I 0659$, and HIO660 genes. We observed that HI1631 gene is missing in all Hae strains analyzed - BPF or not. There is no described function and homologs for HI1631, a putative gene that is believed to encode a cytoplasmic product related in DNA uptake or transformation (Davis et al., 2001) whose expression is competence induced (Redfield et al., 2005). The difficulty of genetically manipulating Hae remains a mystery, Hae further studies on how the deletion of HI1631 or other genes could affect competence in Hae are in progress.

We, the authors, believe that more investigations surrounding the unique virulence of Hae associated with BPF are needed and should be encouraged. Transcriptomic - RNAseq or array, and proteomic profiling would be a major next step in the characterization of important virulence determinants in Hae-BPF. Heterologous expression of others potential virulence factors besides HadA would be an interesting approach to determine the specific contributions to Hae virulence in vitro and in vivo.

\section{Acknowledgements}

This work was financed by the São Paulo Research Foundation (FAPESP; Grants no. 2011/01319-5, 2012/150463, 2018/09874-7, CNPq 304222/2017-8). Gabriel Picirillo Gomide received grants to FAPESP: 2018/07808-7. Daisy Machado received grants to FAPESP 2013/00847-3.

\section{Conflict of Interest}

The authors declare no conflict of interest.

\section{Author contributions}

RFCP, LMH and ML conceived the study; RFCP, T.H.T and ML conducted and supervised the experiments in animal model; RFCP, DM, JPOG and ML analyzed the data; RFCP, GPG and ML wrote the draft manuscript. All authors read and approved the final version.

\section{References}

Arenas J, Paganelli FL, Rodriguez-Castano P, Cano-Crespo S, van der Ende A, van Putten JP and Tommassen J (2016) Expression of the gene for Autotransporter AutB of Neisseria meningitidis affects biofilm formation and epithelial transmigration. Front Cell Infect Microbiol 6:162.

Bartlett JG (2006) Narrative review: the new epidemic of Clostridium difficile-associated enteric disease. Ann Intern Med 145 (10):758-764.

Brenner DJ, Mayer LW, Carlone GM, Harrison LH, Bibb WF, Brandileone MC, Sottnek FO, Irino K, Reeves MW et al. (1988) Biochemical, genetic, and epidemiologic characterization of 
Haemophilus influenzae biogroup aegyptius (Haemophilus aegyptius) strains associated with Brazilian purpuric fever. J Clin Microbiol 26:1524-1534.

Carlone GM., Gorelkin L, Gheesling LL, Hoiseth SK, Mulks MH, O'Connor SP, Weyant RS, Myrick JE, Mayer LW and Arko RJ (1989) Potential virulence factors of Haemophilus influenzae biogroup aegyptius in Brazilian purpuric fever. The Brazilian Purpuric Fever Study Group. Pediatr Infect Dis J 8:245-247.

Cury GC, Pereira RF, Hollanda LM and Lancellotti M (2014) Inflammatory response of Haemophilus influenzae biotype aegyptius causing Brazilian Purpuric Fever. Braz J Microbiol 45:1449-1454.

Dagert M and Ehrlich SD (1979). Prolonged incubation in calcium chloride improves the competence of Escherichia coli cells. Gene 6:23-28.

Davis J, Smith AL, Hughes WR and Golomb M (2001) Evolution of an autotransporter: domain shuffling and lateral transfer from pathogenic Haemophilus to Neisseria. J Bacteriol 183:46264635.

Diep BA, Carleton HA, Chang RF, Sensabaugh GF and PerdreauRemington F (2006) Roles of 34 virulence genes in the evolution of hospital- and community-associated strains of methicillin-resistant Staphylococcus aureus. J Infect Dis 193:1495-1503.

Harrison LH, Simonsen V and Waldman EA (2008) Emergence and disappearance of a virulent clone of Haemophilus influenzae biogroup aegyptius, cause of Brazilian purpuric fever. Clin Microbiol Rev 21:594-605.

Hollanda LM, Cury GC, Pereira RF, Ferreira GA, Sousa A, Sousa EM and Lancellotti M (2011) Effect of mesoporous silica under Neisseria meningitidis transformation process: environmental effects under meningococci transformation. J Nanobiotechnology 9:28.

Li MS, Farrant JL, Langford, PR and Kroll JS. 2003. Identification and characterization of genomic loci unique to the Brazilian purpuric fever clonal group of $H$. influenzae biogroup aegyptius: functionality explored using meningococcal homology. Mol Microbiol 47:1101-1111.

Mell JC, Shumilina S, Hall IM and Redfield RJ (2011) Transformation of natural genetic variation into Haemophilus influenzae genomes. PLoS Pathog 7:e1002151.

Pereira RFC, Mofatto LS, Silva ACA, Alves DA, Machado D, Theizen TH, Pereira GAG, Levy CE, Hollanda LM, Carazzolle MF et al. (2019) Draft whole-genome sequences of Haemophilus influenzae Biogroup aegyptius strains isolated from five Brazilian Purpuric Fever cases and one conjunctivitis case. Microbiol Resour Announc 8: e00642-19.

Pereira RFC, Alves DA, Jacinto RK, Hollanda LM, Verinaud LMC, Machado CML and Lancellotti M (2011) Effects of Neisseria meningitidis infection in tumor gliobastoma cell line NG97: Respiratory pathogen inducing apoptosis. J Bacteriol Parasitol 2:1-5.

Quinn FD, Weyant RS, Worley MJ, White EH, Utt EA and Ades EA (1995) Human microvascular endothelial tissue culture cell model for studying pathogenesis of Brazilian purpuric fever. Infect Immun 63:2317-2322.

Redfield RJ, Cameron AD, Qian Q, Hinds J, Ali TR, Kroll JS and Langford PR (2005) A novel CRP-dependent regulon controls expression of competence genes in Haemophilus influenzae. J Mol Biol 347:735-747.

Rubin LG (1995) Role of the 145-kilodalton surface protein in virulence of the Brazilian purpuric fever clone of Haemophilus influenzae biogroup aegyptius for infant rats. Infect Immun 63:3555-3558
Rubin LG and Carlone GM (1989) An infant rat model of bacteremia with Brazilian purpuric fever isolates of Haemophilus influenzae biogroup aegyptius (Haemophilus aegyptius). The Brazilian Purpuric Fever Study Group. Pediatr Infect Dis J 8:247-248.

Rubin LG and Rizvi A (1991) Antibody to a 145-kilodalton outer membrane protein has bactericidal activity and protective activity against experimental bacteremia caused by a Brazilian purpuric fever isolate of Haemophilus influenzae biogroup aegyptius. The Brazilian Purpuric Fever Study Group. Infect Immun 59:4576-4582.

Rubin LG and St Geme JW 3rd (1993) Role of lipooligosaccharide in virulence of the Brazilian purpuric fever clone of Haemophilus influenzae biogroup aegyptius for infant rats. Infect Immun 61:650-655.

Santana-Porto EA, Oliveira AA, da-Costa MR, Pinheiro A, Oliveira C, Lopes ML, Pereira LE, Sacchi C, Araujo WN and Sober J (2009) Suspected Brazilian purpuric fever, Brazilian Amazon region. Emerg Infect Dis 15:675-676.

Segada LM and Lesse AJ (1997) Creation of an isogenic P1-deficient mutant of Haemophilus influenzae biogroup aegyptius. Gene 204:185-194.

Serruto D, Spadafina T, Scarselli M, Bambini S, Comanducci M, Hohle S, Kilian M, Veiga E, Cossart P, Oggioni MR et al. 2009. HadA is an atypical new multifunctional trimeric coiled-coil adhesin of Haemophilus influenzae biogroup aegyptius, which promotes entry into host cells. Cell Microbiol. 11:1044-1063.

Sinha S, Mell JC and Redfield RJ (2012) Seventeen Sxy-dependent cyclic AMP receptor protein site-regulated genes are needed for natural transformation in Haemophilus influenzae. J Bacteriol 194:5245-5254.

Strouts FR, Power P, Croucher NJ, Corton N, van Tonder A, Quail MA, Langford PR, Hudson MJ, Parkhill J, Kroll JS and Bentley SD (2012) Lineage-specific virulence determinants of Haemophilus influenzae biogroup aegyptius. Emerg Infect Dis 18:449-457.

Vandesompele J, De Preter K., Pattyn F, Poppe B, Van Roy N, De Paepe A and Speleman F (2002) Accurate normalization of real-time quantitative RT-PCR data by geometric averaging of multiple internal control genes. Genome Biol 3:1-34.

Varela JN, Amstalden MC, Pereira RF, Hollanda LM, Ceragioli HJ, Baranauskas V and Lancellotti M (2014) Haemophilus influenzae porine ompP2 gene transfer mediated by graphene oxide nanoparticles with effects on transformation process and virulence bacterial capacity. J Nanobiotechnol 12:14.

Weyant RS, Quinn FD, Utt EA, Worley M, George VG, Candal FJ and Ades EW (1994) Human microvascular endothelial cell toxicity caused by Brazilian purpuric fever-associated strains of Haemophilus influenzae biogroup aegyptius. J Infect Dis 169:430-433.

\section{Supplementary material}

The following online material is available for this article: Table S1 - Oligonucleotides used in this work.

Table S2 - Stability coefficient (M-value) for candidate genes. Table S3 - RQ values for las. tabA1/tahA1, and hadA.

Associate Editor: Daisy Maria Fávero Salvadori

License information: This is an open-access article distributed under the terms of the Creative Commons Attribution License (type CC-BY), which permits unrestricted use, distribution and reproduction in any medium, provided the original article is properly cited. 